\title{
Severe gastroparesis after catheter ablation for atrial fibrillation
}

\author{
Jonathan S. Zipursky MD, Steven Shadowitz MDCM MSC
}

Cite as: CMAJ 2017 March 6;189:E368. doi: 10.1503/cmaj.160335

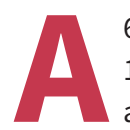

65-year-old woman presented to hospital following 10 days of vomiting, epigastric pain, abdominal bloating and decreased bowel movements. She had a history of peptic ulcer disease and atrial fibrillation. Her medications were amiodarone, rivaroxaban and omeprazole. Ten days prior, she had undergone a catheter-directed cryoablation procedure for symptomatic atrial fibrillation.

Computed tomography of her abdomen showed severe stomach distention (Figure 1) with upstream dilation of the esophagus. An upper endoscopy showed no obstructing lesion at the pylorus. A gastric-emptying test showed gastroparesis with inability to propulse radiotracer from the proximal to distal stomach and small bowel (86\% of retained gastric contents at four hours postingestion). Clinical findings and imaging were consistent with postablation gastroparesis.

Nine months after admission, the patient was seen in followup. Her symptoms were unresolved despite trials of metoclopramide and domperidone. She was started on prucalopride (a 5-hydroxytryptamine (4) receptor agonist).

At subsequent follow-up 12 months after admission, her symptoms had resolved; a gastric-emptying test showed marked improvement $(26 \%$ of retained gastric contents at four hours postingestion).

Gastroparesis is an uncommon extracardiac complication of catheter ablation procedures for atrial fibrillation. A large case series of patients who underwent percutaneous catheter ablation estimated the prevalence of gastroparesis after radiofrequency ablation and cryoablation procedures at $10 \%$ and $6 \%$, respectively. ${ }^{1}$ The most likely mechanism is periesophageal vagal nerve injury: the vagus nerve innervates the stomach and pyloric sphincter, and runs adjacent to the left atrium and inferior pulmonary veins. ${ }^{1}$ Predictors of symptomatic gastroparesis following cryoablation may include lower mean temperatures on the inferior pulmonary veins during the procedure and smaller left atrial diameter. ${ }^{1}$

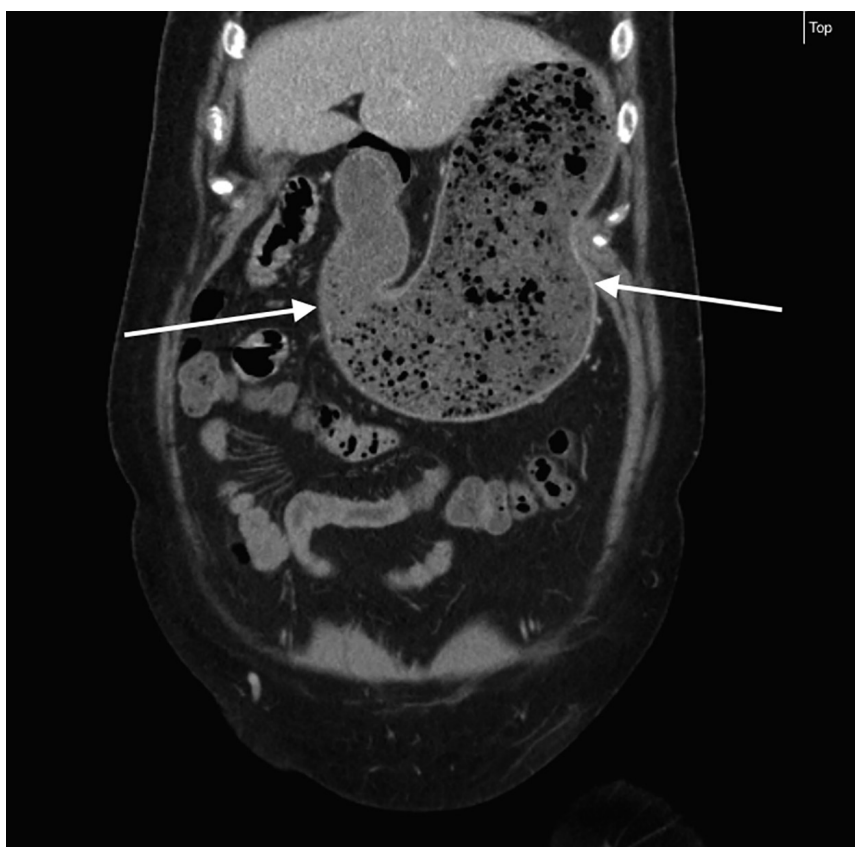

Figure 1: Computed tomography scan (coronal view) of the abdomen of a 65 -year-old woman showing marked distention of the stomach (arrows), no obvious obstructing lesion and retention of food products secondary to gastroparesis.

Management of gastroparesis includes prokinetic agents [e.g., metoclopramide, domperidone, erythromycin or 5-hydroxytryptamine (4) receptor agonists] and antiemetics. ${ }^{2}$ In general, symptoms do not persist beyond six months after the ablation procedure. ${ }^{1}$

\section{References}

1. Aksu T, Golcuk S, Guler TE, et al. Gastroparesis as a complication of atrial fibrillation ablation. Am J Cardiol 2015;116:92-7.

2. Camilleri M, Parkman HP, Shafi MA, et al. Clinical guideline: management of gastroparesis. Am J Gastroenterol 2013;108:18-37.

\section{Competing interests: None declared.}

This article has been peer reviewed.

The authors have obtained patient consent.

Affiliations: Department of Medicine (Zipursky, Shadowitz), University of Toronto; Division of General Internal Medicine (Shadowitz), Sunnybrook Health Sciences Centre, Toronto, Ont.
Acknowledgement: The authors thank Sheldon Singh for his comments and advice during preparation of this manuscript.

Correspondence to: Jonathan Zipursky, jonathan.zipursky@mail.utoronto.ca 